\title{
The need to transform Science Communication from being multi-cultural via cross-cultural to intercultural
}

\author{
Simon Schneider ${ }^{1,2}$ and Liv Heinecke ${ }^{3}$ \\ ${ }^{1}$ Institute of Earth and Environmental Science, University of Potsdam, Potsdam, 14476, Germany \\ ${ }^{2}$ Research Focus Earth Sciences, University of Potsdam, Potsdam, Germany \\ ${ }^{3}$ Institute for Mathematics, University of Potsdam, Potsdam, Germany
}

Correspondence: Simon Schneider (simschne@uni-potsdam.de)

Received: 1 July 2018 - Revised: 14 January 2019 - Accepted: 17 January 2019 - Published: 31 January 2019

\begin{abstract}
When dealing with issues that are of high societal relevance, Earth sciences still face a lack of acceptance, which is partly rooted in insufficient communication strategies on the individual and local community level. To increase the efficiency of communication routines, science has to transform its outreach concepts to become more aware of individual needs and demands. The "encoding/decoding" concept as well as critical intercultural communication studies can offer pivotal approaches for this transformation.
\end{abstract}

\section{Introduction}

Scientists, in particular Earth scientists, experience, that while developing, conducting and communicating research projects with topics such as climate change, natural hazards or sustainable land management they have to accept communication and interpretation routines of their stakeholders and audiences. These are mostly deeply rooted in different value and belief systems. Focusing on non-economic dimensions, these belief systems have been called folk knowledge, native knowledge, indigenous knowledge and traditional knowledge among others. But all these terms bear a sublime notion of hierarchy, where academic (western) knowledge is seen as dominant. Today, we are aware of this potential clash between academic and indigenous knowledge. Nevertheless, too often communication, dissemination, and education strategies do not consider the challenge of intercultural communication. At the moment we are, at its best, stranded at a stage of cross-cultural communication. To fully integrate, accept and appreciate indigenous knowledge, science and science communication has to move on and perform the transition into intercultural communication.

Until today, there is no commonly accepted generic definition of Science Communication. Some scholars distinguish between science journalism, public relation of science and science communication (Hoffjann, 2007). Others divide science communication into communication that shares scientific content with other social subsystems and internal communication processes within the sciences (HerrmannGiovanelli, 2013). To solve this issue, it seems appropriate to use a definition for Science Communication that has been suggested by Burns et al. (2003):

The use of appropriate skills, media, activities, and dialogue to produce one or more of the following personal responses to science: Awareness, Enjoyment, Opinion-forming, Understanding. Science Communication may involve science practitioners, mediators, and other members of the general public, either peer-to-peer or between groups.

According to this definition, Science Communication - especially in the field of Earth science research - has to deal increasingly with issues, results, and content that is of great importance for a wide range of stakeholder groups and audiences. Until now, strategies in communication - as one of the core elements of science management - were woven around vague target audiences such as the broader public, children, or political decision makers. But modern communication research emphasizes that the crude and inadequate categorization of audiences is insufficient and might be even contra productive (Goebel, 2017; Keane, 1995). Present-day social science claims that these assumable homogenous target audiences are non-existent (e.g Weingart, 2003; Bommes 
and Tacke, 2011). Instead, management and communication strategies should appreciate the concepts developed within structural functionalism and intercultural research. Within structural functionalism, audiences and stakeholder groups are conceptualized as complex compositions of individuals that can be described by socio-cultural similarities, but nevertheless consists of individuals (e.g. Nisbet and Scheufele, 2009).

Within this article, we try to sensitize scientists, science communicators and science managers for the challenges within this transition. We will commence by deducing the core concepts of diverse knowledge systems. This will be followed by reviewing the theoretical concept of science communication, which will lead to a clear definition of the challenges faced by scientists who have to communicate to stakeholders and audiences with diverse socio-cultural backgrounds. Finally, we attempt to formulate a set of recommendations for future science communication and management strategies.

\section{Systemic context}

At the interface of natural and social sciences, we have to describe and define some core concepts, which will be used within the following discourse. Notably, it is crucial to distinguish between academic and indigenous knowledge (an overview is given in Tsuji and Ho, 2002). Academic knowledge hereby stands for a knowledge system that has been called Western Science, Newtonian Science and others (Lindberg, 1992; Berkes et al., 2000; Aikenhead, 2001). Nevertheless, some scholars are uncomfortable with the term western science (Medin and Bang, 2014). They worry that using the term western science undermines the contribution of other traditions, including Indigenous, East Asian and Islamic cultures. The idea that the west is the primary source for scientific knowledge should not be inadvertently reinforced (Raj Pandya, director of the American Geophysical Union's Thriving Earth Exchange, personal communication, 2018). While it is probably true that western worldviews frame much of current scientific practice, we should acknowledge that there has been a fair amount of appropriation and westernization of other knowledge. Social scientists and ethnologists have called this phenomenon science colonialism (Whitt, 2009).

The term academic knowledge therefore is meant as a synonym that includes what Levi-Strauss (1962) and Feyerabend (1987) named western science but also embeds research and development in industry as well as modern research at universities all over the world. Levi-Strauss (1962) characterized western science as "supremely abstract" while indigenous knowledge seems to be "extremely concrete". The term indigenous knowledge on the other hand is meant as a concept that is rooted in social experiences, observations and believes, shared by communities that "often becomes encoded in rituals and in the cultural practices of everyday life" (Berkes et al., 2000). Indigenous science therefore reflects "... the memories and knowledges that arise from Indigenous peoples' living heritages as societies with stories, lessons, and long histories of having to be well-organized to adapt to seasonal and inter-annual environmental changes." (Whyte, 2017).

\section{Theoretical concepts}

Within this chapter, we want to define a theoretical framework, which will help us to propose a transition in science communication. Thus, we will focus on science communication as an exemplary and crucial element of science management.

Williams (1958) describes society or even community as a conglomerate of unique core elements. These unique elements can be called individuals. On a macro-level, these individuals can be organizations or enterprises, whereas on a micro-level, these individuals are individual human beings. Thereby, a community is fractionized on a socio-cultural level as each core element or individual has its own history, its own experiences to share, and its own values and belief systems. If different core elements share a similar, but not necessarily an equal history, experiences or belief systems, they are likely to form a community with a shared culture (Martin and Nakayama, 2010; UNESCO, 1982, 2001). Martin (2017) resorts in this respect to the concept of dialectics of culture and communication. This is important as we need to accept and appreciate the individual differences within a community in order to gain insight into the multifaceted interpretation routines. Only by recognizing the differences, we have the means for addressing individuals successfully within management and communication, or as Williams (1958) stated:

\section{Wherever we have started from, we need to listen to others who have started from a different posi- tion. We need to consider every attachment, ev- ery value, with our whole attention; for we do not know the future, we can never be certain of what may enrich it; we can only, now, listen to and con- sider whatever may be offered and take up what we can.}

As a result, the definition of stakeholders and audiences has to acknowledge the complex, inhomogeneous nature of targeted audiences. Within relationship management (customer relations or key account management) this is stateof-the-art (Leung et al., 2014). Science communicates and manages its interactions with industry partners already today on a micro-level, taking the specific needs, demands and expectations from individual industry partners into account. Science management, for example, deals with global 
distribution partners for new technologies in a very different way than with local engineering firms and companies. On the other hand, within the public sphere, science tends to address a homogenous mass audience, which is often called "the public". By doing so, science neglects the true nature of "the public" as being an amalgamation of unique core elements with individual histories and contexts.

Within the last decades, scholars from communication sciences have constantly developed the theoretical model of communication further. Today, the simple Aristotelian Sender-Receiver-Model of communication has been substituted with Shannon and Weaver's Information Theory Model (1949) and diverse enhancements (for example the introduction of social context by Maletzke, 1963; the inclusion of the four core dimensions of information by Schulz von Thun, 1981; the separation of sender and receiver processes on the basis of constructivist approaches e.g. von Glasersfeld, 1981). The key innovation within the development process of communication models has been the implementation of "encoding" and "decoding" (Hall, 1973) based on constructivist ideas (Krotz, 2009; Burgoon et al., 2010). Both aspects include a very individualistic procedure of information processing and can describe sources for misunderstandings. If the encoding is done without appreciation of diverse decoding-mechanisms, communication is likely to fail. Science management already accepts this by conducting different strategies to different stakeholder sets (e.g. on the level of identifying audiences as "the public", "politicians", or "the industry"), but the level of understanding for the encoding-decoding conundrum is so far mostly insufficient. Present science management aims to identify diverse needs, demands, and expectations via public-opinion polls and various media-surveys (e.g. for Germany: Wissenschaft im Dialog, 2017, for the EU: European Commission, 2005, 2017). Nevertheless, identification is not equal to understanding. Therefore, science communication often succeeds only on a shallow level mostly on a cognitive dimension. School education, a very sub-set of science communication, is a great example for this: schools abbreviate the decoding process within pupils by transferring scientific research results from an academic language into a child-appropriate language. While this is plausible, individual decoding routines are rarely taken into account, although education research has shown that - for example - boys and girls decode information in slightly different ways (OECD, 2015). Differences in decoding have also been reported to depend on the professional family background of children (Bourdieu, 2001; for the combined effects of gender and social status of children on the perception of science see Lühe et al., 2017). These differences in decoding become even more apparent if children from different cultural backgrounds are observed (Aikenhead and Jegede, 1999). It is therefore important for science communication to change its routine of defining its target audiences, and to appreciate the strong inhomogeneous character of the audience.
All this is addressed in the Contextual Model of Intercultural Communication (CMIC; Neuliep, 2006). The advantage of the CMIC is that it takes all kinds of context into account. Therefore, this model is not limited to classical definitions of culture, but looks rather at physical, social or even psychological context and their impact on the communication process. This is, at least to some extent, contrasting the theory of structural functionalism, where all stakeholders or actors should be seen as independent. The CMIC on the other hand proclaims that all stakeholders and actors are linked by context (Holliday, 2011). In addition, the previously mentioned sublime notion of hierarchy within the communication process is also recognized within the CMIC as sociorelational context. By being aware of the interdependencies of contexts and their influence on the communication process itself, intercultural communication becomes manageable. In an ideal scenario the project planning should include an indepth stakeholder analysis, which takes the scientists individual and audience specific deciphering routines into account. This is not always possible, as scientific managers and coordinators are often only hired if the project is granted. However, we still highly recommend a thorough analysis of the aims and wishes for outcomes linked with planned communication and engagement of specific parts of the public e.g. via a workshop in the planning phase, employing professional advice of communication and/or outreach specialists. For further recommendations please see Sect. 6.

\section{Theoretical concept of the transfer from multi to inter-cultural}

A society that contains several cultural or ethnic groups is often referred to as multicultural (Goldberg, 1995; Taylor, 1994). This can be observed for example in classrooms as well as in major cities around the world, where people with different cultural roots live, learn, or work alongside one another. While their cultural groups do not seem self-contained, they do not necessarily engage in interactions with individuals or groups from other cultures. Communication can be observed between individuals or groups of different cultures (Fig. 1a). Luhmann (1975) and others observed that communication needs to be open for connectivity ("Anschlußfähigkeit") to other topics to become continuous, sustainable communication. Multi-cultural communication, because commonalities are missing, cannot offer spoken connectivity. Therefore, communication in multicultural settings tends to be a singularity rather than a continuum.

The term cross-cultural addresses observed differences of cultures (Schaffer and Riordan, 2003). Cross-cultural communication respects differences striving to understand and acknowledge these. It can lead to or induce individual change, but will not lead to collective transformations (Fig. 1b). Characteristic for cross-cultural societies is that "one culture is often considered 'the norm' and all other 
(a)

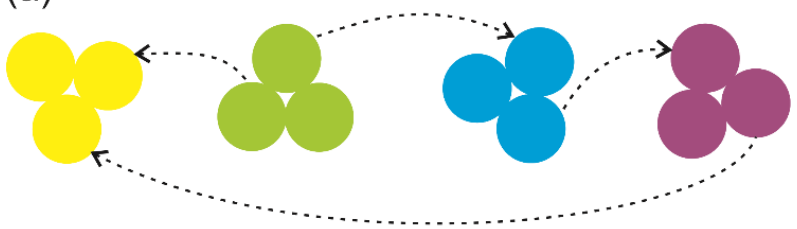

(b)

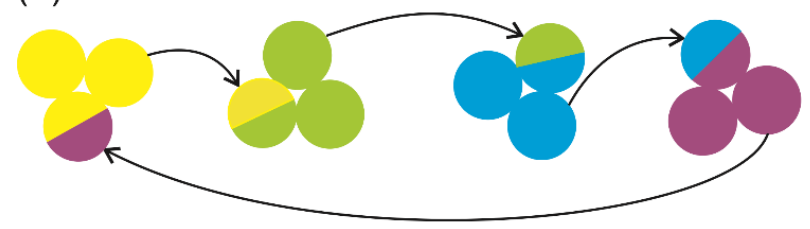

(c)

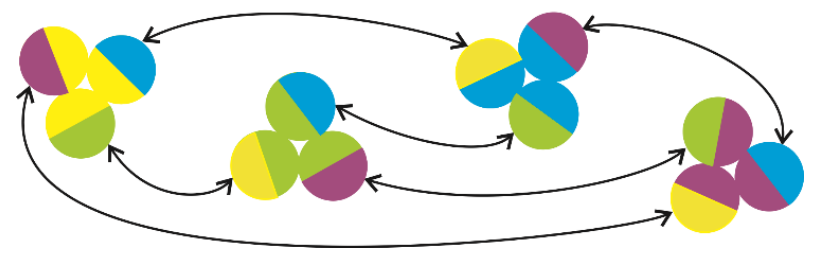

Figure 1. Schematic image depicting (a) multicultural, (b) crosscultural and (c) intercultural (adapted from Schriefer, 2018).

cultures are compared or contrasted to the dominant culture" (Schriefer, 2018). Within cross-cultural communication, a more sustainable communication process can be observed. Following the argument that communication needs to offer connectivity (Luhmann, 1975), communication tends to become a lasting discourse about specific thematic issues. However, an expansion into additional themes seems to be difficult or even not feasible at all. Examples can be found in numerous studies analyzing environmental issues all over the world. While native communities and indigenous knowledge are considered valuable sources for information and long-term observation, individual concerns, indigenous perceptions and concepts are rarely taken into account. The cross-cultural character can be observed e.g. within projects that include public talks and debates at a project phase where the scientific concept of the project is already set. Nevertheless, the project's concept is already set and fixed; local communities and residence are informed about the project goals, but ideas and recommendations from within the local community are not considered further. Oftentimes, these projects integrate the local workforce into sampling and data assimilation, but integrative approaches to local sites, local values, and local perceptions of nature are not implemented. The interaction with the local community stays on a simple communication level. Information - scientific and traditional knowledge - is shared, sometimes even discussed, but there is no expansion into other topics and themes than the core research interest. Thus, multi-cultural projects provide op- portunities for dialogue, for sharing knowledge and to solve project related issues in a cooperative manner. However, a deep mutual appreciation and understanding reaches most of the time not further than the projects framework.

Intercultural communities are characterized by a deep understanding and respect for other cultures (UNESCO, 2013). Intercultural communication therefore seeks mutual exchange of ideas and in-depth discourse about cultural norms. It aims towards the development of deep relationships between cultures. As a result, within intercultural societies, no one is left unchanged (Fig. 1c). There is a constant dynamic re-building of social norms, values, needs, and demands. Intercultural communication becomes a continuous process, which is not only related to a single topic or issue. The establishment of long-term relations (as characterized e.g. by sustainable communication routines) can be seen as indicators for an intercultural character of a project. While bringing a project onto the intercultural level needs time, the benefits are lasting and often reach far beyond the primary research aim. By learning from each other, by accepting and appreciating the perspectives and interpretations of the other, a deeper understanding for concerns and demands can be achieved. Within intercultural projects, the co-design of research conceptions seems an integral element. Thus, scientists have to reach out to local communities as soon as possible and at best in the project-design phase. Methods such as the Photovoice approach or the Mobile Oral History method can help to initiate inter-culturality.

To create sustainable and lasting effects, communication strategies have to address the encoding-decoding conundrum with a deeper understanding of why both might be significantly different from each other. To do so, the socio-cultural environment or context has to be taken into account. Within the concept of socio-cultural context, encoding as well as decoding are strongly influenced by values, believes, and experiences of individuals. If the socio-cultural context between the participants of communication is the same or at least closely related to one another, communication can be successful. If those contexts differ significantly, a transitory service has to be provided. While encoding, we have to consider the way communication might be decoded and vice versa. Natural scientists have developed the concept of transfer functions to describe the output value for each possible input into a process. Hall (1973), when talking about encoding and decoding processes, already introduced the idea of transfer functions to the communication theory. The aim is to predict the decoding process in more detail. While the transfer function can be seen as a complex function with a high number of unknown socio-cultural variables (e.g. belief, values, ethics and moral elements, historic and socio-political as well socio-economic parameters), it seems clear that by identifying at least some socio-cultural background parameters, communication as well as management strategies become more efficient. Furthermore, the transfer function of communication processes is time-dependent. While culture is a non- 
static condition, the above mentioned variables can change with time (Sorokin, 1985; Hofer et al., 2010). Thus, one of the major tasks for science communication will be to analyze in detail the diverse socio-cultural contexts of its stakeholders continuously and adjust the communication strategy.

Over the last decade, polar research (other examples are sparse, but can also be found in Central and Southern Africa, South America and Oceania) has shown that such transfer functions for science communication and management can be derived merely from experience. The socio-cultural variables were observed and experienced by researchers, which has been actively engaged in local communities. Here, the cooperation with Inuit communities is crucial not only for the sake of scientific success, but for the scientific process itself as well as for safety reasons in this extreme environment. Therefore, the transition from multi- via cross- to intercultural cooperation has been widely implemented by Earth and Environmental scientists working in the High Arctic. The following section will highlight some examples of measures taken to integrate local communities and the prevailing native knowledge systems into research strategies.

\section{Indigenous Stakeholder Involvement in Research co-design - an Example from Arctic Research}

The Alfred-Wegener-Institute, Helmholtz Centre for Polar and Marine Research (AWI) conducts numerous scientific studies in the Arctic, including in the northern Yukon in Canada. Here the researchers have been increasingly engaging in dialogue with local communities in order to shape the research activities to be performed. Traditionally, the focus has been on changes to the natural environment but this focus has morphed into a more holistic approach to science, encompassing the view of both the Inuvialuit and the research community. Most of the work takes place on Qikiqtaruk Herschel Island Territorial Park and on the Yukon Coast, which are highly significant to Inuvialuit culture. Field work in the area is therefore subject to a thorough licensing and consultation process. This process involves several Inuvialuit communities, though licensing is primarily based in Inuvik and stakeholder dialogue in Aklavik. Inuvik is inhabited all year round with more than 3000 people, and serves as a starting point for expedition teams before going into the field further up north. Aklavik is located further to the West and hosts approximately 600 inhabitants. Several meetings took place with the Aklavik Hunters and Trappers Committee and/or the Wildlife Management Advisory Council (North Slope) in order to exchange on best practices and identify Inuvialuit research priorities in the area. Several presentations were held in Inuvik at the local research center (Western Arctic Research Center) to showcase examples of the research activities to the local community. These meetings were open to the entire community and provided a great venue to exchange with local stakeholders.
The priority is now to engage both "western scientists" as well as local communities in a co-design approach in research activities and to include local stakeholders early in the process. This approach is conditional to time, trust and commitment on both sides and requires a will to transcend cultural differences in order to achieve the greater good and most importantly to devise activities that are directly relevant to northerners. It shall also rely on an equal appreciation and strong involvement of traditional and scientific knowledge in the research process.

An example from this ongoing collaboration is the study by Irrgang et al. (2019), in which rates of shoreline change are used in order to project coastal changes for the future and assess their impact on the human and natural environment along the coast. The focus of the study is on the vulnerability of Inuvialuit cultural sites to coastal changes. Many of these sites are located along the coast and currently threatened by erosion. Irrgang et al. assembled a team of scientists, a local Parks Canada officer and the Inuvialuit leader of the Qikiqtaruk Herschel Island Territorial Park to identify the sites at risk, determine the relevance of these sites from the Inuvialuit perspective and assess their vulnerability using historical documents, Inuvialuit knowledge and remote sensing techniques. Some of the outputs of this study were vulnerability maps, including high resolution mapping of Tapqaq (Shingle Point), an Inuvialuit summer camp.

These efforts create the rationale behind a new project funded by the European Union in the EU-Horizon 2020 Framework. The project is called "Nunataryuk" (an Inuvialuit term for "land to sea"), which started in 2017 and will run for five years. The consortium includes 26 partners from 11 countries (Nunataryuk.org, 2018). This large endeavor will advance our understanding of permafrost coastal erosion processes, greenhouse gas release from permafrost degradation (including subsea permafrost), but also determines the impacts of permafrost thaw on human health and infrastructure. This work will be performed through a constant engagement of local and global stakeholders. The project management will include representatives from northern communities and yearly meetings, engagement and consultation will ensure that the project focuses not only on scientific but on northern priorities as well. Ultimately, the project aims at co-designing targeted "Adaptation and Mitigation" strategies building on the transdisciplinary work performed by the investigators and the knowledge and questions provided by local and global stakeholders. Stakeholder involvement and communication with policy makers and local communities is thus an essential part of the project and its legacy will primarily lie in the dialogue established between the research community and local stakeholders. 


\section{Approaches to inter-cultural co-design via communication}

First approaches to move towards inter-culturality within science can be found in tools to enhance the co-design of scientific project conceptions via different communication tools, e.g. Photovoice (Wang and Burris, 1994) and Mobile Oral Histories (Riley and Harvey, 2007). To utilize the full potential that lies within these techniques, science foundations as well as project leaders and managers have to be aware that these methods need additional time, budget and manpower. Nevertheless, the knowledge gain and the momentum that can be gathered from using these methods promotes the success and sustainability of the research in question. The Photovoice method seeks to "emphasize community participation for the purpose of social action" (Kuratani and Lai, 2011) and "builds on a deep, historical foundation of individuals and communities blending images and words to express needs, history, culture, problems, and desires" (Nykiforuk et al., 2011). Within a Photovoice study, a first introduction of the overall research theme is given to local communities (a detailed process description is given by Rabinowitz, 2018). This introduction has to be informal, and a level of familiarity with the community should be prioritized. In a second phase, community members are trained in photographic techniques. This element serves for two major purposes: (1) it will result in high quality feedback from the participants and (2) it is perceived as a personal knowledge gain from participating individuals, which leads to an increased identification with the research topic (Wang and Burris, 1994). While the training phase is seen as a crucial element for most studies, it seems necessary to skip the training phase to allow for a more personal and unbiased, organic outcome (Gosselink and Mylykangas, 2008) of the Photovoice approach within highly personal, religious or otherwise sensible research topics. Within a third phase, community members are asked to produce a set of photos that are related to the research topic. Here, no rules or guidelines for individual interpretations are given. It seems wise to conduct at least one workshop for participating individuals during the third phase to initiate new ideas and thoughts through sharing experience amongst the "photographers". Finally, a community exhibition is conducted, during which project scientists and community members can share their thoughts and discuss the individual interpretations of the research issues. The feedback coming from the local community should then be included into the project concept. This will not only enrich the concepts with local perspectives, but will help to create entry points for community members to participate and contribute to the research (Nykiforuk et al., 2011). While Photovoice is already widely used within medical and social studies, its potential for Earth and environmental research studies are obvious. Nevertheless, due to its quite complex implementation, Photovoice has not been applied extensively in Earth sciences.
Another method to foster inter-culturality is the Mobile Oral Histories approach. The Mobile Oral History (MOH) method is a combination of traditional oral history interviews and reflections on particular places and landscapes. While landscapes and places are crucial for local communities and bear meanings that are rarely articulated by local residents, $\mathrm{MOH}$ seeks to reveal these meanings. By visiting the places during the course of the interview itself, the significance of these places to the interviewee can be elicited. Like Photovoice, $\mathrm{MOH}$ serves to facilitate opportunities for expression of personal memories and inherited knowledge, and provides a platform for discussion and sharing of perceptions about place, values, and memories for wider community groups (Coherit and OAS, 2015). MOH will therefore offer a valuable "in-situ" opportunity to residents to express these values, their significance, and the deeper meaning these places have for them. While planning $\mathrm{MOH}$-studies, special considerations should be made in respect to diversity of age and gender, cultural, social and economic context, as well as to geographical location. Those considerations are important criteria for the selection process of interview subjects as well as of interviewees. Like Photovoice, this approach to local communities is time and resource consuming. The benefits are that local communities will feel involved and integrated, and that researchers will gain an insight into the cultural and social context, which will be entered by them in the course of their work.

True inter-cultural co-design and inter-cultural cooperation demands additional resources. Photovoice and $\mathrm{MOH}$ are only two examples of respective approaches, but both show that additional time, financial and human resources are needed. Moreover, there is a demand for inter-cultural communication skills and the sensibility for cultural differences skills that are required from each individual scientist. Science foundations and sponsors have to recognize and acknowledge the need to establish such competences as well as to finance appropriate approaches within the first conceptualization of research projects.

\section{Conclusion and Recommendations}

While there are some examples of inter-cultural cooperation and communication within the Earth sciences, there still is a need to better understand the composition of the diverse audiences. If science communication is seen as an integral part of science management, intercultural competences have to be implemented in management structures. By achieving a detailed understanding and appreciation of local knowledge and belief systems, a sustainable partnership can not only facilitate to organize research in a more effective way, but also to answer the specific needs, demands, and expectations of local communities. Following Martin (2015) the proposed transfer from multi- via cross- to inter-cultural communication strategies demands further research in the area 
of critical intercultural communication on three dimensions: (1) Research has to move beyond individual-focused, reductionistic models to frameworks in order to capture a more holistic, relational, and spiritual view of intercultural communication competence; (2) Science has to develop an understanding that there is no such concept as a national cultural group that might be presumed as homogenous and stable. Instead, science has to acknowledge the fluid, dynamic, contested nature of cultures, multiple cultural identities, and intercultural interactions; (3) Science has to become aware and acknowledge that power relations are part of every intercultural encounter. Academic science should appreciate local and native knowledge as an equal set of scientific wisdom that has to be integrated into interpretive routines. To address all three dimensions of intercultural communication, a paradigm shift from multi- to inter-cultural communication has to be aspired. The concept of transfer functions in intercultural communication models - as suggested in this article - can be a valuable tool to conduct such a shift.

Data availability. No datasets used in this manuscript; please refer to references.

Author contributions. The authors contributed in equal parts to the theoretical deduction, the analysis of exemplary research projects and management approaches, and to the writing of this manuscript.

Competing interests. The authors declare that they have no conflict of interest.

Special issue statement. This article is part of the special issue "Project management in geosciences: systems and practices for high-impact research".

Acknowledgements. We thank Michael Fritz, Anna Irrgang and Hugues Lantuit for discussions and insight into the design of projects conducted. Simon Schneider is funded through the Ministry of Science, Research and Culture (MWFK) of the state of Brandenburg, Germany. The research of Liv Heinecke has been partially funded by the Deutsche Forschungsgemeinschaft through grant CRC 1294 "Data Assimilation". We acknowledge the support of the Deutsche Forschungsgemeinschaft and Open Access Publishing Fund of University of Potsdam.

Edited by: Luisa Cristini

Reviewed by: Magdalena Brus and one anonymous referee

\section{References}

Aikenhead, G.: Integrating Western and Aboriginal Sciences: Cross-Cultural Science Teaching, Res. Sci. Ed, 31, 337-355, https://doi.org/10.1023/A:1013151709605, 2001.

Aikenhead, G. and Jegede, O. J.: Cross-Cultural Science Education: A Cognitive Explanation of a Cultural Phenomenon, J. Res. Sci. Teach., 36, 269-287, 1999.

Berkes, F., Colding, J., and Folke, C.: Rediscovery of traditional ecological knowledge as adaptive management, Ecol. Appl., 10, 1251-1262, https://doi.org/10.1890/10510761(2000)010[1251:ROTEKA]2.0.CO;2, 2000.

Bommes, M. and Tacke, V.: Netzwerke in der funktional differenzierten Gesellschaft, VS Verlag, Wiesbaden, 2011.

Bourdieu, P.: Wie die Kultur zum Bauern kommt. Über Bildung, Schule und Politik, VSA, Hamburg, 2001.

Burgoon, J. K., Guerrero, L. K., and Floyd, K.: Nonverbal communication (1 ed.), Allyn \& Bacon, Boston, MA, 2010.

Burns, T., O'Connor, D., and Stockmayer, S.: Science Communication: A contemporary Definition, Public Underst. Sci., 12, 183 202, 2003.

Coherit and OAS (Organization of American States): Elicitation of Community Heritage Values and Place Perception, available at: http://coherit.com/projectfiles/DeliverableGuide_2_ 2.pdf (last access: August 2018), 2015.

European Commission: Europeans, Science and Technology. Special Eurobarometer 224/Wave 63.1 TNS Opinion \& Social, available at: http://ec.europa.eu/commfrontoffice/publicopinion/ archives/ebs/ebs_224_report_en.pdf (last access: November 2018), 2005.

European Commission: Climate Change. Special Eurobarometer 459/Wave EB87.1 TNS Opinion \& Social, https://doi.org/10.2834/92702, 2017.

Feyerabend, P.: Farewell to reason, Verso, London, UK, 1987.

Goebel, P. H.: Integrierte Kommunikation als Zukunftsaufgabe, in: Modernes Personalmanagement, edited by: Rosenberger, B., Springer Gabler, Wiesbaden, 2017.

Goldberg, D. T.: Multiculturalism: a Critical Reader, WileyBlackwell, Cambridge, Mass., 1995.

Gosselink, C. A. and Myllykangas, S. A.: The leisure experiences of older US women living with HIV/AIDS, Health Care Women In., 28, 3-20, https://doi.org/10.1080/07399330601001402, 2007.

Hall, S.: Encoding/decoding in Television Discourse, in: Centre for Contemporary Cultural Studies: Culture, Media, Language: Working Papers in Cultural Studies, 1972-79, Hutchinson, London, 1973.

Herrmann-Giovanelli, I.: Wissenschaftskommunikation aus der Sicht der Forschenden - Eine Qualitative Befragung in den Natur- und Sozialwissenschaften, UVK Verlagsgesellschaft, Konstanz, 2013.

Hofer, M., Reinders, H., and Fries, S.: Wie sich Werte ändern ein zieltheoretischer Vorschlag zur Erklärung individuellen und gesellschaftlichen Wertewandels, Z. Entwickl. Padagogis., 42, 26-38, https://doi.org/10.1026/0049-8637/a000003, 2010.

Hoffjann, O.: Journalismus und Public Relations - Ein Theorieentwurf der Intersystembeziehungen in sozialen Konflikten, 2. erw. Auflage, VS Verlag für Sozialwissenschaften, Wiesbaden, 2007.

Holliday, A.: Intercultural Communication and Ideology, SAGE, London, 2011. 
Irrgang, A., Lantuit, H., Gordon, R. R., and Pisko, A.: Impacts of past and future coastal changes on the Yukon coast - threats for cultural sites, infrastructure, and travel routes, Arctic Science, in press, 2019.

Kaene, J.: Structural transformations of the public sphere, The Communication Review, 1, 1-22, https://doi.org/10.1080/10714429509388247, 1995.

Krotz, F.: Stuart Hall: Encoding/Decoding und Identität, in: Schlüsselwerke der Cultural Studies, edited by: Hepp, A., VS Verlag, Wiesbaden, https://doi.org/10.1007/978-3-531-91839-6_17, 2009.

Kuratani, D. L. G. and Lai, E.: TEAM Lab - Photovoice Literature Review, available at: https://cpb-us-e1. wpmucdn.com/sites.usc.edu/dist/0/198/files/2018/08/

Photovoice-Literature-Review-FINAL-22ltfmn.pdf (last access: August 2018), 2011.

Leung, K., Ang, S., and Tan, M. L.: Intercultural Competence, Annu. Rev. Organ. Psych., 1, 489-519, 2014.

Levi-Strauss, C.: La pensee sauvage, Librarie Plon, Paris, France, 1962 (English translation, The savage mind, University of Chicago Press, Chicago, Illinois, USA), 1966.

Lindberg, D. C.: The Beginnings of Western Science - the European scientific tradition in philosophical, religious, and institutional context, prehistory to A.D. 1450, University of Chicago Press, Chicago, 1992.

Lühe, J., Becker, M., Neumann, M., and Maaz, K.: Geschlechtsspezifische Leistungsunterschiede in Abhängigkeit der sozialen Herkunft. Eine Untersuchung zur Interaktion zweier sozialer Kategorien, Z. Erziehwiss., 20, 499-519, https://doi.org/10.1007/s11618-016-0720-4, 2017.

Luhmann, N.: Selbst-Thematisierung des Gesellschaftssystems. Über die Kategorie der Reflexion aus der Sicht der Systemtheorie, in: Soziologische Aufklärung 2. Aufsätze zur Theorie der Gesellschaft, edited by: Luhmann, N., Springer VS, Wiesbaden, 72-102, 1975.

Maletzke, G.: Psychologie der Massenkommunikation, Verlag Hans Bredow Institut, Hamburg, 1963.

Martin, J.: Revisiting intercultural communication competence: Where to go from here, Int. J. Intercult. Rel., 48, 6-8, https://doi.org/10.1016/j.ijintrel.2015.03.008, 2015.

Martin, J.: Dialectics of Culture and Communication, The International Encyclopedia of Intercultural Communication, Wiley \& Blackwell, Hoboken, NJ, https://doi.org/10.1002/9781118783665.ieicc0215, 2017.

Martin, J. and Nakayama, T.: Intercultural Communication in Context, 5th edition, McGraw-Hill, New York, 2010.

Medin, D. and Bang, M.: Who's asking? Native science, western science, and science education, MIT Press, Cambridge, Mass., 2014.

Neuliep, J. W.: Intercultural Communication - a contextual approach, SAGE, London, 2006.

Nisbet, M. C and Scheufele, D. A.: What's next for science communication? Promising Directions and Lingering Interactions, Am. J. Bot., 96, 1767-1778, https://doi.org/10.3732/ajb.0900041, 2009.

Nunataryuk.org: https://www.nunataryuk.org/, last access: June 2018.

Nykiforuk, C. I. J., Vallianatos, H., and Nieuwendyk, L. M.: Photovoice as a Method for Revealing Community Perception of the
Built and Social Environment, Int. J. Qual. Meth., 10, 103-124, https://doi.org/10.1177/160940691101000201, 2011.

OECD (Organisation for Economic Co-operation and Development): The $\mathrm{ABC}$ of Gender Equality in Education: Aptitude, Behaviour, Confidence, available at: http://www.oecd. org/pisa/keyfindings/pisa-2012-results-gender.htm (last access: April 2018), 2015.

Rabinowitz, R.: Implementing Photovoice in your Community. Community Tool Box, Center for Community Health and Development, University of Kansas, Lawrence, KS., available at: https://ctb.ku.edu/en/table-of-contents/assessment/ assessing-community-needs-and-resources/photovoice/main, last access: October 2018.

Riley, M. and Harvey, D.: Talking geography: on oral history and the practice of geography, Soc. Cult. Geogr., 8, 345-351, https://doi.org/10.1080/14649360701488765, 2007.

Schaffer, B. and Riordan C. M.: A Review of Cross-Cultural Methodologies for Organizational Research: A BestPractices Approach, Organ. Res. Methods, 6, 169-215, https://doi.org/10.1177/1094428103251542, 2003.

Schriefer, P.: What's the difference between multicultural, intercultural, and cross-cultural communication? Spring Institute, Denver, Col., available at: https://springinstitute.org/whatsdifference-multicultural-intercultural-cross-culturalcommunication/, last access: 1 May 2018.

Schulz von Thun, F.: Störungen und Klärungen, Psychologie der zwischenmenschlichen Kommunikation, Rowohlt, Reinbek, 1981.

Shannon, C. E. and Weaver, W.: The mathematical Theory of Communication, Board of Trustees of the University of Illinois, Urbana, 1949.

Sorokin, P.: Social and Cultural Dynamics, Routledge, New York, 1985.

Taylor, C.: Multiculturalism, Extended paperback edition, Princeton University Press, Princeton, NJ, 1994.

Tsuji, L. J. S. and Ho, E.: Traditional Environmental Knowledge and western Science: In Search of Common Ground, The Canadian Journal of Native Studies XXII, 2, 327-360, 2002.

UNESCO: Mexico City declaration on cultural policies, UNESCO, Paris, available at: http://www.culturalrights.net/descargas/ drets_culturals401.pdf (last access: May 2018), 1982.

UNESCO: Universal declaration on cultural diversity, available at http://unesdoc.unesco.org/images/0012/001271/127162e. pdf (last access: April 2018), 2001.

UNESCO: Intercultural Competence - Conceptual and Operational Framework, available at: http://unesdoc.unesco.org/ images/0021/002197/219768e.pdf (last access: April 2018), 2013.

von Glaserfeld, E.: Einführung in den radikalen Konstruktivismus, in: Wissen, Sprache und Wirklichkeit. Wissenschaftstheorie Wissenschaft und Philosophie, Vol 24, Vieweg + Teubner Verlag, Wiesbaden, https://doi.org/10.1007/978-3-322-91089-9_17, 1987.

Wang, C. C. and Burris, M. A.: Empowerment through Photo novella: Portraits of participation, Health Educ. Quart., 21, 171186, 1994.

Weingart, P.: Wissenschaftssoziologie, transcript Verlag, Bielefeld, 2003. 
Whitt, L.: Science, Colonialism, and Indigenous Peoples: The Cultural Politics of Law and Knowledge, Cambridge University Press, Cambridge, UK, 2009.

WiD (Wissenschaft im Dialog): Wissenschaftsbarometer, Wissenschaft im Dialog GmbH, Berlin, 2017.
Williams, R.: Culture and Society, Penguin, Harmondsworth, 1958.

Whyte, K.: Indigenous Climate Change Studies: Indigenizing Futures, Decolonizing the Anthropocene, English Language Notes, Forthcoming, SSRN, available at: https://ssrn.com/abstract= 2925514 (last access: April 2018), 2017. 